\title{
Complications of Endourologic Procedures: A Review on Iatrogenic Ureteral Perforation
}

\author{
Julia E. de la Cruz (JE de la Cruz) ${ }^{1, *}$, Esther Morcillo (E Morcillo) ${ }^{2}$, Luis Resel Folkersma (L \\ Resel-Folkersma) ${ }^{3}$, Sara Álvarez (S Alvarez) ${ }^{4}$, Francisco M. Sánchez Margallo (FM Sanchez- \\ Margallo) ${ }^{5}$, Federico Soria (F Soria) ${ }^{6}$ \\ 1,2,5,6 Jesus Uson Minimally Invasive Surgery Centre.km 41, N-521, 10071 Caceres, Spain \\ ${ }^{3}$ Hospital Clinico San Carlos. Prof Martín Lagos, 28040 Madrid, Spain \\ ${ }^{4}$ Hospital Universitario Ramon y Cajal. Ctra. Colmenar Viejo, km. 9,100, 28034 Madrid, Spain
}

*Corresponding Author: Julia E. de la Cruz (JE de la Cruz). Jesus Uson Minimally Invasive Surgery Centre.km 41,N-521, 10071 Caceres, Spain.E-mail: jecruz@ccmijesususon.com

\begin{abstract}
The aim of this study is to describe ureteral perforation as a complication of endourologic procedures; its incidence, risk factors, complications and treatment. Ureteral perforation is an injury that involves the entire thickness of the ureteral wall; whose incidence rate is less than $2 \%$. It is related to the caliber of the equipment, the duration of the intervention, the surgeon's experience, the characteristics and location of the stones and the condition of the ureter prior to the intervention. Late diagnosis or inadequate management may lead to more serious complications such as urinoma, fever, and long-term stricture and obstructive uropathy. The treatment of this complication in the majority of cases consists in Double-Jstenting with a success rate over $80 \%$; when this treatment fails, the following therapeutic options are Percutaneous Nephrostomy and reconstructive surgery.
\end{abstract}

Keywords: Endourology, ureteroscopy, perforation, complications, risk factors of perforation, stricture, extravasation

\section{INTRODUCTION}

Ureteroscopy is a first-line technique for the diagnosis and treatment of many upper urinary tract conditions. One of its main uses is intracorporeal lithotripsy [1], which has managed to take over extracorporeal shock wave lithotripsy (ESWL) and percutaneous nephrolithotomy in selected patients [1]. In addition, ureteroscopy has become a very efficient tool for the diagnosis and treatment of low risk urothelial cell carcinoma and other nonneoplastic conditions of the upper urinary tract[1,2]. According to Geraghty et al systematic review, from 1996 to 2016, the number of annual ureteroscopicprocedures for the treatment of urolithiasis has increased by $251,8 \%$, which indicates a global increase of $17 \%$ in comparison with other techniques previously mentioned ${ }^{[3]}$. This is mainly due to urologists increased experience and improvementsin technical equipment including miniaturization, the introduction of disposable equipment and an improvement in optical quality and that of surgical instruments ${ }^{[4,5]}$.
These advances have enabled a drastic reduction in the percentage of complications from the first series, which showed a rate of $20 \%{ }^{[6]}$, to the last multicentric series, with a global rate of intraoperative and postoperative complications of $6.3 \%$ and $3.5 \%$ respectively ${ }^{[5]}$.Complications can be classified as intraoperative and postoperative $^{7}$ and they are listed in Table1 $1^{[5,7,8,9,10,11,12,13,14]}$.

Table1.Complications of endourologic procedures

\begin{tabular}{|l|l|}
\hline \multicolumn{1}{|c|}{$\begin{array}{c}\text { COMPLICATIONS OF } \\
\text { ENDOUROLOGIC } \\
\text { PROCEDURES }\end{array}$} & INCIDENCE \\
\hline INTRAOPERATIVE & \\
\hline Mucosal lesion and false passage & $2.8 \%-7 \%^{8,9}$ \\
\hline Bleeding & $0.9-2.5 \%^{10}$ \\
\hline Failed Access to the ureter & $1.6 \%^{5,7}$ \\
\hline $\begin{array}{l}\text { Proximal migration of fragments } \\
\text { during lithotripsy }\end{array}$ & $3.9 \%^{8}$ \\
\hline Ureteral perforation & $<2 \%^{5,11}$ \\
\hline Ureteral avulsión to adjacent & $0.1-0.3 \%^{5,11}$ \\
\hline $\begin{array}{l}\text { Injuries to } \\
\text { structures/vascular injuries }\end{array}$ & $0.4 \%^{12,13}$ \\
\hline $\begin{array}{l}\text { Malfunctioning or breakage of } \\
\text { instruments }\end{array}$ & $0.8 \%^{8,9}$ \\
\hline
\end{tabular}




\begin{tabular}{|l|l|}
\hline POSTOPERATIVE & $1.3-3 \%$ \\
\hline Fever & $0.6-1.8 \%^{11}$ \\
\hline Infection & $1.35-3.2 \%^{9,14}$ \\
\hline Extravasation & $0.3 \%{ }^{5}$ \\
\hline Stricture & $1.4 \%^{14}$ \\
\hline $\begin{array}{l}\text { Postobstructive diuresis, in bilateral } \\
\text { obstruction or patient with solitary } \\
\text { kidney }\end{array}$ & \\
\hline
\end{tabular}

Complications have traditionally been classified as major and minor, acute or chronic. These classifications are subjective and there is no agreement on them among urologists [14]. It is necessary to classify the different complications in order to enable comparisons between the outcomes found in different studies as well as to determine standardized guidelines for their correct management $[14,8,15]$.

The classification systems used to categorize ureteroscopic complications are mainly: the Modified Clavien Classification System (MCCS) or Clavien-Dindo, the Modified Satava Classification System and the PostUreteroscopic Lesion Scale system (PULS).

The Modified Clavien Classification System (MCCS) or Clavien-Dindo defines and classifies postoperative complications depending on the therapy used for its management [16]. At present the MCCS classification is the most widely accepted method in the field of urology. It is becoming the standard method used for assessing complications in the treatment of upper urinary tract lithiasis[5,14,18].

The Satava classification is one of the most widely used systems to classify intraoperative surgical complications. It originally consisted of 3 grades until Tepeler et al modified this classification in order to adapt it to ureteroscopic complications [8].

"Postureteroscopic Lesion Scale" or PULS refers to a classification system of ureteroscopic lesions [15]. This system consists of the urologist's visual assessment of ureteral damage when the ureteroscopic procedure is completed. At the same time, the scale determines the best treatment recommendations for each lesion grade. It consists of 5 grades according to lesion depth and extent of the ureteral circumference affected [15].

Also, regarding ureteral lesions caused by ureteral access sheaths, Traxer et al have developed a visual classification system consisting of 5 grades. Lesions are classified from 0 to 4 according to lesion depth [19].
The objective of this review is to describe ureteral perforation as a complication of endourologic procedures, its incidence, risk factors, complications and treatment.

\section{MAterials And Methods}

In order to reach our objectives, a review of scientific papers was carried out selecting those publications that assessed ureteral perforation as a complication resulting from endourologic procedures.

The searches were carried out using the bibliographic resource PubMed using the English key words "uretereal injury", "ureteroscopy", "ureteral access sheath", "perforation", "extravasation", "stricture", "treatment" and "guidelines". In order to refine the search AND and OR were used as Boolean operators.

The search was limited to papers in English and the time period chosen comprised the years between 2000 and 2017, even though these papers also included references to older articles. Two copy authors (JEC, FS) identified the papers and selected studies that assessed perforation caused by endourologic procedures, including semirigid and flexible ureteroscopy, as well as perforation caused by ureteral access sheaths.

\section{RESUltS}

Following an exhaustive analysis of all papers initially selected, a total of 39 were included in this review: 6 systematic revisions, 4 multicentric studies, 6 non-systematic reviews, 9 prospective studies, 10 retrospective studies and 4 guidelines from the European Association of Urology (Figure 1).

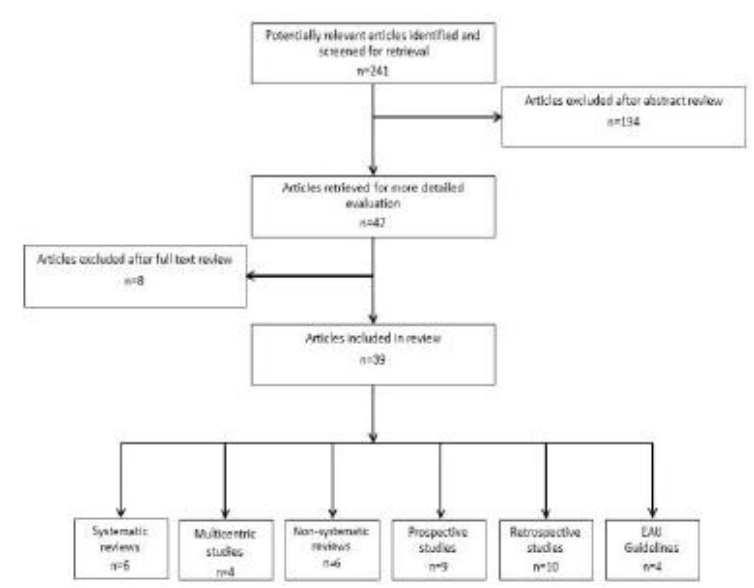

Figure1. The study selection process 


\section{DISCUSSION}

\subsection{Perforation}

\subsubsection{Incidence and risk factors}

Ureteral perforation is a lesion consisting of a partial rupture of the ureteral circumference which involves the whole ureteral wall thickness ${ }^{[15,19]}$. When a perforation is detected during an endourologic procedure, the endoscopic image is characterised by the presence of periureteral fat and/or retroperitoneal tissue ${ }^{[19]}$ (Figure 2). However, when the rupture is complete an avulsion exists, which is a more severe complication ${ }^{[15,19]}$. The causes of perforation are the large diameter of ureteroscopes in comparison with the ureteral diameter, the insertion and traumatic advancement of these, intraureteral lithotripsy, ureteral dilatation and use of ureteral access sheaths ${ }^{[7,20]}$.

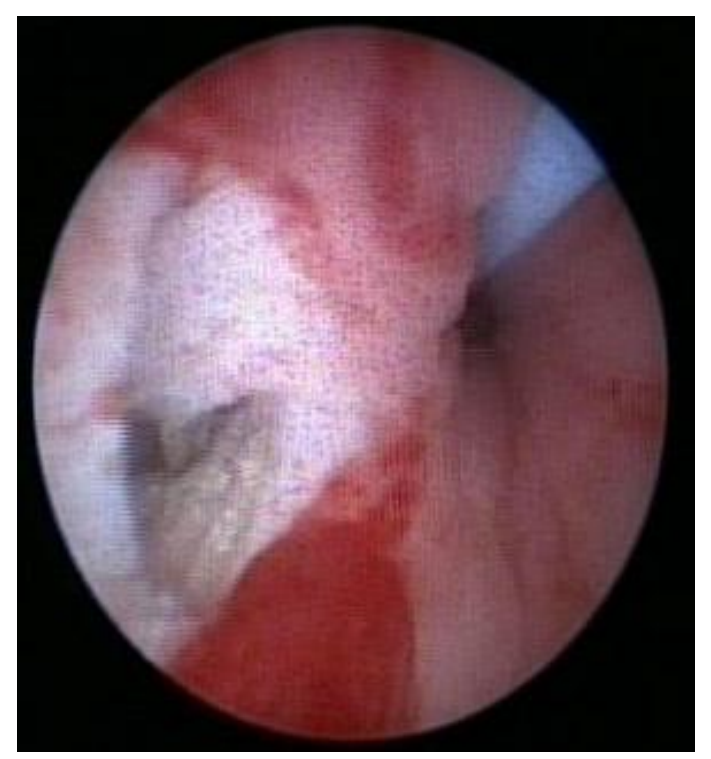

Figure2. Ureteral perforation during ureteroscopy. Periureteral fat can be seen at the site of perforation.

Regarding the level of incidence, the early series reflect a perforation incidence of up to $17 \%^{[21]}$. These high percentages can be attributed to larger equipment and to urologists' lack of experience in endoscopic techniques three decades $\mathrm{ago}^{[21]}$. The incidence has decreased in the clinical series over the last ten years, due to better designed equipments and surgical instruments, causing fewer traumas. Improvements such as a decrease in diameter and size, telescoped and non-traumatic ends and the development of hydrophilic ancillary equipment, specifically designed for ureters ${ }^{22}$. In current publications, rates vary from 0.4 to $6.25 \%^{[22,23]}$. Regarding the main clinical series, two multicentric studies from the Clinical Research Office of the Endourological Society (CROES) report perforation percentages of $1 \%$ and $0.7-1.6 \%$, respectively ${ }^{[5,11]}$.

The ureter is a fragile organ which might be damaged during endourologic procedures. The distension produced by the endoscope and instruments compromises vascular flow, thus exposing the ureteral wall to a higher lesion risk $^{[19]}$. Consequently, the diameter of ureteroscopes is a risk factor for the onset of perforation. A correlation exists between ureteroscope diameter and incidence of ureteral lesions due to ureteroscopy ${ }^{[24]}$. In that respect, Tepeler et a ${ }^{[8]}$ observed that in 1.208 patients all significant complications defined as perforation and avulsion arose when using a $9.5 \mathrm{Fr}$ ureteroscope, whereas the procedures performed with a 4.5Fr ureteroscope did not show ureteral trauma. In relation to the endoscope, there are no significant differences regarding perforation when using a semirigid ureteroscope versus using a flexible ureteroscope ${ }^{[11]}$. However, the lithotripsy method does influence perforation incidence, this being lower when using a Ho: YAG laser versus pneumatic lithotripsy ${ }^{[25]}$.

There is an association between perforation and longer surgery duration. Schuster et al describe that procedures which resulted in perforations took an average of 101 minutes,as opposed to 63-minute duration for procedures that were free of complications ${ }^{[4]}$. In addition, lack of experience increases perforation risk $^{[4,9]}$. Endourology is a discipline requiring a high level of technical skills and therefore with a long learning curve. Perforation percentage is significantly higher when procedures are performed by urologists with less than two years of experience in endourology, due to more experienced urologists treating patients with less manipulation of the upper urinary tract ${ }^{[4,8]}$.

A higher or lower perforation risk also depends on the characteristics of lithiasis. El-Nahas et $\mathrm{al}^{[26]}$ found that in addition to surgeon's inexperience, lithiasis size and location and whether the stone was impacted or not, are significant factors affecting perforation incidence.There is a higher perforation incidence in patients with calculi measuring over $15 \mathrm{~mm}^{[23,9,27]}$. Specifically, $62.5 \%$ of perforations occur in lithiasis measuring over 20 $\mathrm{mm}^{[22]}$. There are significant differences regarding the location of perforation in proximal 
and lumbar ureter versus distal ureter, being $1.6 \%$ and $0.7 \%$ respectively ${ }^{[11]}$. In addition, $64 \%$ of the perforations at lumbar ureter occur with impacted lithiasis. This suggests that the treatment of a lithiasis impacted in the lumbar ureter could probably cause perforation ${ }^{[11]}$. This occurs as a result of the impacted lithiasis causing chronic inflammation, ureteral edema and interstitial fibrosis, all of which weakens the ureteral wall, thus increasing the likelihood of perforations ${ }^{[28,29]}$. On the other hand, regarding their location, stones at proximal and lumbar ureter are larger because they cannot descend. This location and size make them more difficult to approach and increases the duration of surgery, which is also a risk factor for ureteral perforation, as mentioned above ${ }^{[11]}$. Consequently the treatment of large impacted lithiasis at proximal and lumbar ureter implies a higher risk of ureteral lesions and perforation.

The use of ureteral access sheaths in flexible ureteroscopy causes distension leading to ischemia at ureteral level. Reperfusion after retrieving these sheaths exposes the ureter to free radicals which damage and weaken the ureteral wall ${ }^{[19]}$. Traxer et al describe a $3.3 \%$ perforation in intrarenal surgery procedures performed with ureteral access sheath ${ }^{[19]}$, being the absence of stenting prior to the procedures the main risk factor. Particularly the placement of a preoperative double-J stent for sheath procedures reduces the risk of severe ureteral lesion by seven fold, including perforation ${ }^{[19]}$. However, despite the benefits found with the passive dilatation of double-J stents, their routine use is not recommended, as it is not cost-effective and is associated with a deterioration in patients' quality of life $\mathrm{i}^{[30,31]}$. Regarding flexible ureteroscopy procedures with and without ureteral access sheath, there is no significant difference in perforation incidence, being the percentages $1.1 \%$ and $1.2 \%$ respectively ${ }^{[32,33]}$. Table 2 presents a summary of the risk factors associated to ureteral perforation in endourological procedures.

Table2. Risk factors of ureteral perforation in endourological procedures

\begin{tabular}{|l|}
\hline Risk Factors of Ureteral Perforation \\
\hline 1 Ureteroscope's diameter \\
\hline 2 Surgery duration \\
\hline 3 Urologist's experience \\
\hline 4 Lithiasis characteristics \\
\hline 5 Use of ureteral Access sheaths \\
\hline
\end{tabular}

\subsection{Perforation Complications}

\subsubsection{Extravasation And Stricture}

Late detection or inappropriate treatment of perforations is associated with the onset of severe adverse events: urinoma, fever, obstruction, fistula or septicemia. Patients with undiagnosed perforations in the long term present with strictures and non-functional nephroureteral units. Ureteral perforation must be suspected in patients referred with recurrent fever, flank pain or urinary fistula ${ }^{[34]}$.

\subsubsection{Extravasation}

Extravasation is a direct consequence of ureteroscopic perforation ${ }^{[7]}$. Extravasation must be suspected in patients showing symptoms such as persistent flank pain, abdominal distension, ileus, nausea or vomiting, and who underwent endourologic procedures, especially if these were long and complex ${ }^{[7]}$.Symptoms appear one week after surgery and may be associated with extravasations of irrigation fluid, contrast medium, urine, blood and lithiasic fragments ${ }^{[35]}$. Their incidence is $1.35 \%^{[14]}$ although this is probably underestimated as it is not usual to perform a routinary retrograde ureteropyelography after finishing the procedure unless a lesion is suspected ${ }^{[7]}$. Nevertheless, it is possible that only the extravasation of large amounts of fluids leads to clinical symptoms ${ }^{[7,34]}$. When this occurs, it results in urinomas ${ }^{[36]}$. If extravasation of urine occurs with the presence of infective agents such as bacteria, lithiasis fragments and small clots, patients develop secondary infections, abscesses and even septic shock ${ }^{[37]}$. Retroperitoneal fibrosis is another possible consequence of urine extravasation.

Extraureteral migration of lithiasic fragments to the retroperitoneum does not usually have clinical relevance unless the fragments are located intramurally ${ }^{[7]}$. The rate of extraureteral migration of stone fragments in the scientific literature is around $0.2 \%{ }^{[38]}$. When migration is sterile and asymptomatic, a conservative management is recommended. It is very important to give patients adequate information about this condition in order to avoid future mistakes in diagnosis during future radiological exams ${ }^{[10]}$. However, if fragments stay embedded in the ureteral wall, there is an increased risk of secondary strictures to granuloma formation and it is very significant in the case of impacted 
lithiasis $^{[7]}$. Finally, the risk of strictures in migrations to retroperitoneal space is minimum $^{[39]}$.

\subsubsection{Strictures}

Ureteral stricture is a possible late complication of perforation. It is considered a major complication due to its associated side effects, including pain, infection, obstructive nephropathy and even loss of renal unit function ${ }^{[7]}$. The incidence of strictures is usually lower than $1 \%{ }^{[5,22,38]}$. In fact, the CROES reported a $0.3 \%$ stricture incidence ${ }^{[5]}$. The mechanism involved in strictures development is multifactorial and involves several predisposing factors such as ischemia, periureteral fibrosis due to perforations with infected urine extravasation ${ }^{[40]}$, interstitial fibrosis and edema ${ }^{[22]}$.

Strictures are associated with ureteral trauma caused by surgical instruments and management of impacted lithiasis ${ }^{[41]}$. In fact, ureteral perforations and impacted lithiasis have been described as the main risk factors for strictures onset $^{[22,28,29]}$. This is due to the fact that perforation, similarly to other ureteral lesions, leads to various inflammatory changes resulting in ischemic damages to the ureteral wall which increase the probability of postoperative stricture $^{[29]}$. Regarding the relationship between perforation and strictures, in ureteroscopic procedures, $50 \%$ of strictures appear in ureters perforated during those procedures ${ }^{[22]}$. On the other hand, $75 \%$ of ureters perforated during ureteroscopic treatment suffer stricture later ${ }^{[22,29]}$, with a statistically significant relationship between the perforated area of the ureter and the strictured $\operatorname{area}^{[22]}$. This relationship exists even with postoperative stenting for 4-6 weeks ${ }^{[22]}$.

\subsection{Treatment of Perforations and their Complications}

If perforation is suspected, a retrograde ureteropyelography must be performed. Extravasation of the contrast medium confirms perforation. At that moment a decision will be made as to whether stop the endourologic procedure or finish it under safe irrigation control $^{[7]}$.

The first therapeutic choice isthe placement of a double-J ureteral stent by retrograde approach $^{[7,10,38]}$. The double-J stent acts as an internal drainage system and as a scaffold for ureteral healing, allowing collagen bundles to settle properly on the muscular layer. This therapy therefore allows correct remodelling and avoids the problems associated with ureteral healing such as stricture ${ }^{[42]}$. Once stented, the ureter must heal before carrying out any kind of instrumentation in the urinary tract. If retrograde placement of the ureteral stent is not possible, an anterograde approach will be attempted ${ }^{[10,38]}$.Regarding treatment time with double-J stent, recommendations in scientific papers vary from 4 to 8 weeks $^{[15,19,22]}$. According to PULS classification $^{[15]}$, the treatment of a grade 3 perforation consists of double-J stenting for 3-4 weeks, as the urothelial layer needs three weeks to heal ${ }^{[43]}$. Grade 4 perforations which affect over $50 \%$ of the ureteral circumference must be treated with a double-J stent for 6-8 weeks, the approximate time needed for muscular layer healing ${ }^{[43,44]}$. Stenting duration to treat perforations is usually 4-6 weeks ${ }^{[9]}$. However, it has been experimentally observed that 3-weeks provide the same results regarding ureteral healing, which is an advantage, as reducing stenting duration decreases the adverse effects associated with double-J stents ${ }^{[45]}$. When lesions are diagnosed late, the placement of a double-J stent for 8-12 weeks is the first therapeutic option $^{[34]}$. If perforation appears during retrieval of ureteral access sheath, Traxer et al recommend double-J for 3-6 weeks ${ }^{[19]}$.

Despite the efficacy of Double-J stenting, it is related to some adverse effects and complications that affect patients' quality of life ${ }^{[47]}$. Their use remain controversial nowadays ${ }^{[48]}$. The European Association of Urology(EAU) guidelines ${ }^{[49]}$ regarding the treatment of urolithiasis, recommend the postoperative placement of ureteral stents in patients with high risk of complications such as perforation. Ureteral stents are not recommended after uncomplicated ureteroscopies, because they can increase postoperative morbidity. However, the scientific literature supporting these recommendations does not provide clear evidence in order to distinguish a complicated ureteroscopy from an uncomplicated on $e^{[50,51]}$. As of today, perforation is clearly defined as a complication of the endourological procedures whose treatment is necessary ${ }^{[8,14,15]}$.

The treatment of perforations with double-J stent is feasible and effective in most cases, with 
a success rate between $80 \%$ and $94.8 \%^{[8,10,38]}$. However, when the double-J treatment fails, percutaneous nephrostomy and reconstructive surgeries are the next therapeutic options. Nephrostomy alone is not a definite treatment but it does relieve pain, fever and extravasation ${ }^{[34]}$. When transuretral and percutaneous approaches are impossible, reconstructive surgery will be the next choice ${ }^{[10]}$. Percutaneous and reconstructive procedures are performed in $5.2-15 \%$ of the cases ${ }^{[10,38]}$. Ureteral anastomosis, ureterovesical reimplantation in distal lesions, Boari flap ureteroneocystostomy, ileoplasty and self-transplantation are surgery techniques used for the reconstruction of perforated ureters ${ }^{[46]}$. Nephrectomy remains as the procedure of last choice.

It is important a thorough monitoring of the patients who have suffered ureteroscopic perforations to make sure that they do not develop strictures or ureteral obstruction in the future. El-Abd et al recommend performing a follow-up with imaging techniques during 18 months following surgery in all patients who experience intraoperative complications such as perforation $^{[22]}$.

As for complications of perforation and urinoma treatment, any handling of the urinary tract with ureteral extravasation will increase the fluid accumulation in the retroperitoneum and will make more likely the need for reintervention. In addition it is important to consider that the existence of urinoma delays the ureteral healing process $^{[43]}$. Large retroperitoneal urinomas must be drained percutaneously, especially if they are contaminated by infected urine or are symptomatic. If extravasation persists despite percutaneous drainage, ureteral stent and vesical Foley catheter, the placement of a nephrostomy tube will be necessary ${ }^{[7]}$.

Stricture treatment is performed endoscopically by dilatation, endoureterotomy or by reconstructive surgery. The endoscopic treatment of ureteral strictures is prescribed in strictures measuring below $2 \mathrm{~cm}$. Endoureterotomy and balloon dilatations are the two most widely used techniques. Success rates are $53-82 \%$ for endoureterotomy and $13-80 \%$ for balloon dilatation ${ }^{[40]}$. After performing both techniques, double-J stenting is necessary for 1 to 8 weeks $^{[40]}$. The surgical procedure to be used, whether laparoscopic or conventional, will depend on stricture site and length. Distal strictures are usually treated with direct ureteral reimplantation with psoas hitch, whereas proximal strictures require more modern techniques such as Boari flap ureteroneocystostomy, ileal transposition, transureteroureterostomy and renal selftransplantation. Treatment with uretero-ureteral anastomosis is recommended for stricturesof 2-3 $\mathrm{cm}$, whereas ureteroneocystostomy is the ideal technique for strictures measuring $4-5 \mathrm{~cm}$ and strictures measuring 6-10 $\mathrm{cm}$ must be treated with Boari flap ${ }^{[40]}$.

\section{Conclusions}

Ureteral perforation is a minor complication caused by the insertion and traumatic advancement of the ureteroscopes and instrumental, as well as by the weakening of the ureteral wall during endourologic procedures. With an incidence below $2 \%$, it is related to the diameter of ureteroscopes, surgery time, surgeon's experience, lithiasis characteristics and location, and ureter condition before surgery. Late diagnosis or incorrect management may lead to severe complications such as urinoma, fever, and in the long term to stricture and obstructive nephropathy. The treatment of this complication in most cases consists in double-J stenting. When this treatment fails, percutaneous nephrostomy and reconstructive surgeries are the next therapeutic options.

\section{ACKNOWLEDGEMENTS}

The authors would like to thank Fernanda Carrizosa for her essential bibliographical support.

\section{REFERENCES}

[1] Mozafarpour S, Hernandez N, Lipkin M, Eisner BH. Outcomes of ureteroscopy. Minerva Urol Nefrol. 2016;68:560-569.

[2] Rouprêt M, Babjuk M, Compérat E, et al. European association of urology guidelines on upper urinary tract urothelial cell carcinoma: 2015 update. Eur Urol. 2015; 68:868-879.

[3] Geraghty R, Jones P, Somani BK. Worldwide Trends of Urinary Stone Disease Treatment over the last two Decades: A Systematic Review. J Endourol. 2017; 31:547-556.

[4] Schuster TG, Hollenbeck BK, Faerber GJ, Wolf JSJ. Complications of ureteroscopy: analysis of predictive factors. J Urol. 2001; 166:538-540.

[5] de la Rosette J, Denstedt J, Geavlete P, et al. The clinical research office of the endourological society ureteroscopy global study: indications, complications, and outcomes in 11,885 patients. J Endourol. 2014; 28(2):131-139. 
[6] Lytton B, Weiss RM, Green DF. Complications of ureteral endoscopy. J Urol. 1987; 137:649653.

[7] Volkin D, Shah O. Complications of ureteroscopy for stone disease. Minerva Urol Nefrol. 2016; 68:570-585.

[8] Tepeler A, Resorlu B, Sahin T, et al. Categorization of intraoperative ureteroscopy complications using modified Satava classification system. World J Urol. 2014; 32:131-136.

[9] Mursi K, Elsheemy MS, Morsi HA, Ali Ghaleb AK, Abdel-Razzak OM. Semi-rigid ureteroscopy for ureteric and renal pelvic calculi: Predictive factors for complications and success. Arab J Urol. 2013; 11:136-141.

[10] Georgescu D, Mulţescu R, Geavlete B, Geavlete P. Intraoperative complications after 8150 semirigid ureteroscopies for ureteral lithiasis: risk analysis and management. Chirurgia (Bucur). 2014; 109:369-374.

[11] Perez Castro E, Osther PJS, Jinga V, et al. Differences in ureteroscopic stone treatment and outcomes for distal, mid-, proximal, or multiple ureteral locations: The clinical research office of the endourological society ureteroscopy global study. Eur Urol. 2014; 66:102-109.

[12] Rothberg MB, Monga M, Gupta M. Lumbar artery branch injury secondary to ureteroscopic manipulation. J Can Urol Assoc. 2014;8:449450 .

[13] Chiu PK-F, Chan C-K, Ma W, To K-C, Cheung F-K, Yiu M. Subcapsular hematoma after ureteroscopy and laser lithotripsy. J Endourol. 2013; 27:1115-1119.

[14] Ibrahim AK. Reporting ureteroscopy complications using the modified clavien classification system. Urol Ann. 2015; 7:53-57.

[15] Patients U, Wilhelm K, Kuehhas FE, Farin E, $\mathrm{Ph}$ D. Postureteroscopic lesion scale: a new management modified organ injuryscale-evaluation in 435 ureteroscopic patients. J Endourol. 2012;26:1425-30

[16] Dindo D, Demartines N, Clavien P-A. Classification of Surgical Complications. Ann Surg. 2004; 240:205-213.

[17] Clavien PA, Sanabria JR, Strasberg SM. Proposed classification of complications of surgery with examples of utility in cholecystectomy. Surgery. 1992; 111:518-526.

[18] Xu Y, Min Z, Wan SP, Nie H, Duan G. Complications of retrograde intrarenal surgery classified by the modified Clavien grading system. Urolithiasis. 2017; 0(0):0. doi: 10.1007/s00240-017-0961-6..

[19] Traxer O, Thomas A. Prospective evaluation and classification of ureteral wall injuries resulting from insertion of a ureteral access sheath during retrograde intrarenal surgery. J Urol. 2013; 189:580-584.

[20] Schoenthaler M, Buchholz N, Farin E, et al. The Post-Ureteroscopic Lesion Scale (PULS): A multicenter video-based evaluation of interrater reliability. World J Urol. 2014;32:10331040.

[21] Kramolowsky E V. Ureteral perforation during ureterorenoscopy: treatment and management. J Urol. 1987; 138(1):36-38.

[22] El-Abd AS, Suliman MG, Abo Farha MO, et al. The development of ureteric strictures after ureteroscopic treatment for ureteric calculi: A long-term study at two academic centres. Arab J Urol. 2014; 12:168-172.

[23] Kassem A, Elfayoumy H, Elsaied W, Elgammal M, Bedair A. Laser and pneumatic lithotripsy in the endoscopic management of large ureteric stones: a comparative study. Urol Int. 2012;88:311-315.

[24] Francesca F, Scattoni V, Nava L, Pompa P, Grasso M, Rigatti P. Failures and complications of transurethral ureteroscopy in 297 cases: conventional rigid instruments vs. small caliber semirigid ureteroscopes. Eur Urol. 1995; 28:112-115.

[25] Galvin DJ, Pearle MS. The contemporary management of renal and ureteric calculi. BJU Int. 2006; 98:1283-1288. .

[26] El-Nahas AR, El-Tabey NA, Eraky I, et al. Semirigid ureteroscopy for ureteral stones: a multivariate analysis of unfavorable results. J Urol. 2009; 181:1158-1162.

[27] Geraghty R, Abourmarzouk O, Rai B, Biyani CS, Rukin NJ, Somani BK. Evidence for Ureterorenoscopy and Laser Fragmentation (URSL) for Large Renal Stones in the Modern Era. Curr Urol Rep. 2015; 16:4-9.

[28] Roberts WW, Cadeddu JA, Micali S, Kavoussi LR, Moore RG. Ureteral stricture formation after removal of impacted calculi. J Urol. 1998; 159:723-726.

[29] Brito AH, Mitre AI, Srougi M. Ureteroscopic pneumatic lithotripsy of impacted ureteral calculi. Int Braz J Urol. 2006;32:295-299.

[30] Mahajan PM, Padhye AS, Bhave AA, Sovani YB, Kshirsagar YB, Bapat SS. Is stenting required before retrograde intrarenal surgery with access sheath. Indian J Urol. 2009;25(3):326-328. doi:10.4103/09701591.56185 .

[31] Joshi HB, Stainthorpe A, Macdonagh RP, Keeley FX, Timoney AG. Indwelling Ureteral Stents: Evaluation of Symptoms, Quality of Life and Utility. J Urol. 2003; 169(3):10651069.

[32] Traxer O, Wendt-Nordahl G, Sodha H, et al. Differences in renal stone treatment and 
outcomes for patients treated either with or without the support of a ureteral access sheath: The Clinical Research Office of the Endourological Society Ureteroscopy Global Study. World J Urol. 2015; 33:2137-2144.

[33] Geraghty RM, Ishii H, Somani BK. Outcomes of flexible ureteroscopy and laser fragmentation for treatment of large renal stones with and without the use of ureteral access sheaths: Results from a university hospital with a review of literature. Scand J Urol. 2016; 50(3):216219.

[34] El Abd AS, El-Abd SA, El-Enen MA, et al. Immediate and late management of iatrogenic ureteric injuries: 28 years of experience. Arab J Urol. 2015; 13:250-257.

[35] Yanaral F, Ozkan A, Cilesiz NC, Nuhoglu B. Spontaneous rupture of the renal pelvis due to obstruction of pelviureteric junction by renal stone: A case report and review of the literature. Urol Ann. 2017; 9:293-295.

[36] Tonolini M, Villa F, Ippolito S, Pagani A, Bianco R. Cross-sectional imaging of iatrogenic complications after extracorporeal and endourological treatment of urolithiasis. Insights Imaging. 2014; 5:677-689.

[37] Luo XM, Zhang C, Qian HJ, Song C, Yang SX. Characteristics of patients with fluid extravasation during retrograde ureteroscopic holmium laser lithotripsy for renal calculi. Saudi Med J. 2011; 32:1251-1255.

[38] Geavlete P, Georgescu D, NiţĂ G, Mirciulescu V, Cauni V. Complications of 2735 Retrograde Semirigid Ureteroscopy Procedures: A SingleCenter Experience. J Endourol. 2006; 20:179185.

[39] Lopez-Alcina E, Broseta E, Oliver F, Boronat F, Jimenez-Cruz JF. Paraureteral extrusion of calculi after endoscopic pulsed-dye laser lithotripsy. J Endourol. 1998; 12:517-521.

[40] Tyritzis SI, Wiklund NP. Ureteral Strictures Revisited...Trying to See the Light at the End of the Tunnel: A Comprehensive Review. J Endourol. 2015; 29:124-136.
[41] Johnson DB, Pearle MS. Complications of ureteroscopy. Urol Clin North Am. 2004; 31:157-171.

[42] Bhatnagar BN, Chansouria JP. Healing process in the ureter: an experimental study in dogs. J Wound Care. 2004; 13:97-100.

[43] Andreoni CR, Lin H-K, Olweny E, et al. Comprehensive evaluation of ureteral healing after electrosurgical endopyelotomy in a porcine model: original report and review of the literature. J Urol. 2004; 171:859-869.

[44] Rehman J, Ragab MM, Venkatesh R, et al. Smooth-muscle regeneration after electrosurgical endopyelotomy in a porcine model as confirmed by electron microscopy. J Endourol. 2004; 18:982-988.

[45] Soria F, Rioja LA, Blas M, Duran E, Uson J. Evaluation of the duration of ureteral stenting following endopyelotomy: Animal study. Int J Urol. 2006;13:1333-1338.

[46] Cornu JN, Herrmann T, Traxer O, Matlaga B. Prevention and Management Following Complications from Endourology Procedures. Eur Urol Focus. 2016; 2:49-59.

[47] Joshi HB, Okeke A, Newns N, Keeley FXJ, Timoney AG. Characterization of urinary symptoms in patients with ureteral stents. Urology. 2002; 59:511-516.

[48] Bultitude M, Smith D, Thomas K. Contemporary Management of Stone Disease: The New EAU Urolithiasis Guidelines for 2015. Eur Urol. 2016; 69:483-484.

[49] Türk C, Petrrík A, Sarica K, et al. EAU Guidelines on Interventional Treatment for Urolithiasis. Eur Urol. 2016; 69:475-482.

[50] Pengfei S, Yutao L, Jie Y, et al. The results of ureteral stenting after ureteroscopic lithotripsy for ureteral calculi: a systematic review and meta-analysis. J Urol. 2011; 186:1904-1909.

[51] Makarov D V, Trock BJ, Allaf ME, Matlaga BR. The effect of ureteral stent placement on post-ureteroscopy complications: a metaanalysis. Urology. 2008; 71(5):796-800.

Citation: Julia E. de la Cruz (JE de la Cruz), Esther Morcillo (E Morcillo), Luis Resel Folkersma (L ReselFolkersma), Sara Álvarez (S Alvarez), Francisco M. Sánchez Margallo (FM Sanchez-Margallo), Federico Soria (F Soria). Complications of Endourologic Procedures: A Review on Iatrogenic Ureteral Perforation. ARC Journal of Urology.2017; 2(2):17-24. doi: dx.doi.org/10.20431/2456-060X.0202003

Copyright: (C) 2017 Authors. This is an open-access article distributed under the terms of the Creative Commons Attribution License, which permits unrestricted use, distribution, and reproduction in any medium, provided the original author and source are credited. 